\title{
FLUJO VAGINAL EN LA PACIENTE EMBARAZADA
}

\author{
Dr. Jaime Díaz Garzón*
}

Según estadísticas foráneas (1), aproximadamente el $25 \%$ de las mujeres embarazadas presental al examen bacteriológico del flujo vaginal, Trichomonas vaginalis, aunque solo un porcentaje de ellas se queje de síntomas. También en un $25 \%$ de las mujeres embarazadas y que presentan leucorrea, al examen bacteriológico se ha demostrado la presencia de monilias (Candida Albicans).

Nuestro interés ha sido no solo el de hallar la frecuencia de estas dos entidades en nuestro medio hospitalario, sino también el de averiguar qué otros agentes patógenos intervienen como posibles causantes de flujo vaginal. Así mismo, como la Citología vaginal es considerada como un método fidedigno (2) en el diagnóstico de la tricomoniasis vaginal, la hemos comparado como método, con el examen bacteriológico de flujo.

\section{Material y Métodos}

Se revisaron 1.372 de las historias clínicas de pacientes que asistieron al Servicio de Prenatal del Instituto Materno Infantil durante el tiempo comprendido entre el mes de Abril de 1967 y el mes de Mayo de 1969. Para este estudio se tuvieron en cuenta los siguientes parámetros: edad, estado civil, edad gestacional, paridad, presencia o no de flujo, citología vaginal, examen bacteriológico de flujo vaginal (en fresco, Gram, cultivo), y examen parcial de orina. Es de anotar que como no se hizo cultivo especial para hongos, no se consideran valederos los datos estadísticos en relación con estos.

De las 1.372 pacientes, a 1.048 $(76,4 \%)$ se les tomó muestra para Citología vaginal; pero como sólo 106 de las 1.048 con citología tienen examen bacteriológico del flujo, es en este grupo que se puede hacer la comparación citología vaginal - examen bacteriológico, en relación con la tricomoniasis.

\section{Resultados:}

Teniendo en cuenta los parámetros antes mencionados, los resultados fueron los siguientes:

Edad Gestacional:

$\begin{array}{llrl}\text { Entre } 40 \text { y } 36 \text { semanas } & 370 & (35,3 \%) \\ \text { Entre } 35 \text { y } 31 \text { semanas } & 377 & (36 \%) \\ \text { Entre } 30 \text { y } 22 \text { semanas } & 240 & (22,9 \%) \\ \text { Menos de } 21 \text { semanas } & 61 & (5,8 \%)\end{array}$

\section{Edad:}

Las edades límites fueron los 14 y los 46 años, estando la mayoría comprendidas entre los 18 y los 30 años $(85 \%)$.

\footnotetext{
* Instructor Asociado. Depto. de Obstetricia y Ginecología. Universidad Nacional de Colombia.
} 
Estado Civil:

Solteras

Casadas

$637(60,8 \%)$

$411 \quad(39,2 \%)$

Paridad:

Primigestantes

G2 o más

$408 \quad(39,4 \%)$ $640 \quad(60,6 \%)$

Presencia o no de flujo:

$\begin{array}{lll}\text { Primigestantes con flujo } & 230 & (53,6 \%) \\ \text { Primigestantes sin flujo } & 200 & (46.4 \%) \\ \text { G2 o más con flujo } & 410 & (66,4 \%) \\ \text { G2 o más sin flujo } & 208 & (33,6 \%)\end{array}$

Este dato fue aportado por las pacientes al ser interrogadas.

De las 1.048 Citologías tomadas,

$\begin{aligned} & 542 \text { fueron clase } A 1 \\ & 501 \text { fueron clase A2 } \\ & 4 \text { fueron clase A3 } \\ & 1 \text { fueron clase A4 }\end{aligned}$

$(47 \%)$

$(46,8 \%)$

$(0.7 \%)$

1 fueron clase A4

$(0,1 \%)$

De las 430 primigestantes:

251 presentaron Citología Al

179 presentaron Citología A2

$(58,5 \%)$

$(41,5 \%)$

De las 6.18 G2 O multigestantes,

291 presentaron Citología A1

322 presentaron Citología A2

4 presentaron Citología A3

1 presentaron Citología A4

(47\%)

$(52,2 \%)$

$(0,7 \%)$

$(0,1 \%)$

Las pacientes que tuvieron citologías clase $3 \circ 4$, posteriormente fueron exhaustivamente estudiadas y tratadas para su problema tumoral.

La relación Trichomonas-Monilias en las 1.048 citologías, fué la siguiente:

$\begin{array}{lrr}\text { Con Tricomonas } & 202 & (19,3 \%) \\ \text { Con Monilias } & 59 & (5,6 \%) \\ \text { Con Tric. + Monil. } & 3 & (0,3 \%) \\ \text { Negativo } & 784 & (74,8 \%)\end{array}$

De las 202 citologías con Tricomonas,

20 fueron clase $\mathrm{A} 1$

180 fueron clase $A 2$

2 fueron clase $\mathrm{A3}$

$(9,9 \%)$

$(89,1 \%)$

$(1 \%)$

A 106 de las pacientes con citología vaginal se les practicó examen de flujo, con los siguientes resultados:
Tricomonas en 33 casos

$(31,1 \%)$

Monilias en 17 casos

$(16 \%)$

Al comparar los 33 casos de Tricomonas en el examen de flujo con la citología, vemos que en todos los casos menos 1 (32), también aparecen las Tricomonas en la citología ( $97 \%$ ) en cambio, en la orina, de los 33 casos positivos para tricomonas en el examen de flujo, solo aparecen en 5 $(15,1 \%)$.

En relación con las monilias los resultados son aún más satisfactorios en el examen de flujo que en la $\mathrm{Ci}$ tología o el examen de orina:

De las 17 moniliasis diagnosticadas por el examen de flujo, solo 10 $(58,5 \%)$ fueron confirmadas por la citología, y $7(41,5 \%)$ fueron diagnosticadas por el examen de la orina. Excepcionalmente $(3 \%)$ se hallaron tricomonas en la orina, sin haberse hallado éstas en el examen de flujo o en la citología.

En ninguno de los flujos estudiados el agente causante fué único (tricomonas, monilias, E. Coli, estafiloco$\mathrm{co}$, etc.), sino que hubo una asociación de $2 \circ 3$ de ellos.

Además de las tricomonas y monilias ya vistos, los siguientes fueron los gérmenes que causaron la aparición de flujo: (de 106),

$\begin{array}{lrr}\text { Escherichia Coli } & 98 & (92,4 \%) \\ \text { Estafilococo } & 46 & (43,4 \%) \\ \text { Estreptococo } & 12 & (11,3 \%) \\ \text { Hemophilus Vaginalis } & 9 & (8,5 \%) \\ \text { Diploc. Gram (-) tipo Neisser } & 1 & (0,9 \%)\end{array}$

Se halló Bacilo de Doderlein en 16 casos, $(15,1 \%)$. Como no hubo datos al respecto, no se pudo establecer si hubo o no Cervicitis crónica, ya que es bien sabido que esta por sí sola produce flujo "inespecífico".

* Aún sin haberse hecho cultivo para Cándida Albicans. 


\section{Comentarios}

Es realmente notorio el hecho de que pacientes con tricomoniasis vaginal, ya sea en sus formas "latente" o "florida" (3), presentan citología clase 2 o más $(90 \%)$, siendo raro encontrar en estos casos clase 1 (10\%). Hay que recordar que como la tricomoniasis por sí misma puede dar citologías sospechosas (falsas positivas), es necesario hacer tratamiento adecuado y repetir la citología, antes de recurrir a métodos diagnósticos más cruentos. El tratamiento se reduce a administrar metronidazol tanto oral como localmente, siendo los resultados excelentes.

Para la moniliasis el tratamiento de elección es la aplicación local de violeta de genciana (sol. acuosa al 1\%), - la nistatina también localmente. Por el hecho de que este antibiótico no se absorbe en la mucosa intestinal (4), su uso por vía oral no tiene valor en estos casos.

Las sulfas son de gran valor no sólo en el tratamiento de ciertos "flujos inespecíficos", sino también en aquellos producidos por Hemophilus Vaginalis.

El tratamiento local (cremas, soluciones, óvulos etc.) de las afecciones antes mencionadas, es imperativo, pero hay que llamar la atención sobre el cuidado extremo que hay que tener en la aplicación de estas drogas, por el peligro de provocar abortos, partos prematuros etc., o inclusive de causar la muerte por embolia aérea (5), como cuando se aplican duchas a presión.

\section{Conclusiones}

1. El examen de rutina de Citología Vaginal en la mujer embarazada (y no embarazada), es imperativo, no solo por su importancia en el diagnóstico precoz del cáncer del cérvix, sino también por su seguridad diagnóstica en caso de tricomoniasis.

2. La Citología Vaginal y el examen de flujo, tienen el mismo valor en relación con el diagnóstico de tricomoniasis vaginal; en relación con la moniliasis el examen de flujo es francamente superior.

3. La incidencia de tricomoniasis vaginal en nuestras pacientes embarazadas es de un $31,1 \%$; la incidencia de moniliasis, no se pudo establecer puesto que sin cultivo especial para hongos, los resultados no son confiables.

4. En el flujo vaginal, la E. Coli está presente en un $92,4 \%$ de las veces; el estafilococo en un $43,4 \%$; el estreptococo en un $11,3 \%$; el Hemophilus vaginalis en un $8,5 \%$ y según parece, la blenorragia casi ha desaparecido de nuestras pacientes hospitalarias, pues solo hubo un caso $(0,9 \%)$.

\section{BIBLIOGRAFIA}

1 WILLIAMS. Obstetrics, 13th. ed. pp. 333.

2 RUTH GRAHAM. El diagnóstico Citológico. pp. 10.

3 NOVAK and WOODRUFF. Gynecologic \& Obstetric. Pathology. pp. 620 (6th. ed.).

4 GOODMAN and GILMAN. The Pharmacological Basis of Therapeutics, (3rd ed.) pp. 1293.

5 FORBES, G., Air Embolism as complication of vaginal douching in pregnancy. Brit. $M$. J., 2: 529, 1944. 